\title{
Pembuatan Rumah Data Menggunakan Software ArcGIS Sebagai Pangkalan Informasi Dalam Bentuk Peta Digital Pokoh 1, Dlingo, Bantul, Yogyakarta
}

\author{
(Making Data Houses Using ArcGIS Software as Information Base in the Form of \\ Digital Map Pokoh 1, Dlingo, Bantul, Yogyakarta)
}

\author{
Emil Adly \\ Program Studi Teknik Sipil, Fakultas Teknik, Universitas Muhammadiyah Yogyakarta \\ Jalan Brawijaya, Tamantirto, Kasihan, Bantul, DIY
}

\section{ARTICLE INFO}

\section{Article history}

Received : 28 October 2020

Revised : 17 November 2020

Accepted : 24 November 2020

DOI :

http://dx.doi.org/10.33366/jast.v4i2.1645

Keywords

Digital Map

GIS;

Pokoh 1 Hamlet;

Population Information

e-mail corresponding author : emil@umy.ac.id

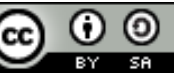

This is an open access article under the Creative Commons AttributionShareAlike 4.0 International License. Any further distribution of this work must maintain attribution to the author(s) and the title of the work, journal citation and DOI. $\underline{\text { CC-BY-SA }}$
ABSTRACT

Population information in a hamlet and data processing is still done manually, which requires a lot of documents, time, and is susceptible to loss; besides that, there are still many hamlets that have not been supported by accurate population maps and accessibility that show the infrastructure for the movement of goods and people. Reduce these problems and introduce the hamlet to technology; it is necessary to update the currently developing technology information and mapping system. This service aims to create a digital map of the hamlet, which contains information about demographic attributes, type of business according to the needs of the hamlet, which can be known as a data house using a Geographic Information System (GIS). Its application is assisted through ArcGIS software, accessed by village and community officials located in Dusun Pokoh 1 Dlingo Village, Dlingo sub-district, Regency Bantul, Yogyakarta Special Region. Implementing this activity starts with socialization to the community, secondary data collection in the form of family cards obtained from the Hamlet Head, taking coordinates using Garmin tools and interviews, which are then inputted using an excel device and analyzed using ArcGIS software. Digital map with clear delineation, high accuracy, Notation depicting houses and facilities following the coordinates equipped with road infrastructure can be convenient to go to tourist areas in the hamlet. With this map, the hamlet apparatus will be more comfortable to do work and provide information related to the population without looking at existing documents and is a car because it can be accessed using a cellular phone anytime and anywhere as long as it has an internet network. Besides, the results obtained are open host as long as they still have a link.

\section{PENDAHULUAN}

Dusun Pokoh 1 adalah salah satu Dusun yang yang berlokasi di Desa Dlingo, kecamatan Dlingo, Kabupaten Bantul, Daerah Istimewa Yogyakarta. Secara geografis Dusun Pokoh 1 berada pada dataran yang tinggi, hutan, alam yang menarik, dengan tingkat perekonomian menengah ke bawah.

Salah satu wisata alam yang bisa di terdapat di Dusun Pokoh adalah air terjun 
Lepo yang menjadi primadona bagi masyarakat Yogyakarta yang haus akan wisata alam, untuk itu berbagai informasi mengenai perkembangan wilayah pariwisata ini juga hingga informasi mengenai penduduk setempat merupakan informasi fital untuk diketahui guna meningkatkan ekonomi mayasrakat sekitar.

Untuk menunjang kemajuan suatu daerah tentunya harus mempunyai sistem yang mendukung untuk mempermudah proses pelaksanaannya. Secara administrasi Dusun Pokoh 1 dalam pengolahan data yang berisi informasi kependudukan masih dilakukan secara manual yang membutuhkan banyak waktu, sehingga untuk memperbarui data administrasi sangatlah tidak efisien dan rentan kerusakan. Oleh karena itu untuk mengurangi permasalahan tersebut perlu dilakukannya pembaharuan dalam sistem informasi Dusun, salah satunya dengan melakukan pemetaan Dusun berbasis Sistem Informasi Geografis (SIG).

Data yang begitu banyak untuk merepresentasikan atau memodelkan fenomena-fenomena yang terdapat di dunia nyata membuat kita seringkali kesulitan dalam mengarsipkannya, karena data-data tersebut masih terpisah satu dengan yang lainnya. Dengan bantuan Sistem Informasi Geografis, kita dapat mengarsipkan (penyimpanan) semua data-data yang penting dalam suatu sistem informasi dan kita juga dapat mengelola, memproses atau memanipulasi, menganalisis, serta menampilkan kembali data-data tersebut [1].

Tujuan pengabdian ini adalah untuk membuat peta digital berbasiskan SIG dalam pengaplikasiannya akan dibantu dengan menggunkan software ArcGIS yang di dalamnya bisa berisi informasi mengenai kependudukan, jenis usaha, fasilitas umum, jalan ataupun berupa atribut dan lain sebagainya sesuai dengan kebutuhan Dusun yang dikenal sebagai rumah data dalam bentuk peta dengan maksud mempermudah perangkat Dusun dalam mengelola dan mendapatkan informasi, memperbaharui data kependudukan Dusun, usaha penduduk, sekaligus dan bagi masyarakat lainnya peta akan berguna sebagai petunjuk arah ke daerah wisata yang terkenal dan terdekat dengan daerah Yogyakarta. Menurut [2] informasi dapat dikatakan sebagai data yang diolah, serta dapat disimpan dalam bentuk tertulis, suara, gambar mati atau gambar hidup, sehingga informasi tersebut pada akhirnya dapat berupa ilmu dan pengetahuan diri.

Saat ini teknologi informasi terus berkembang seiring dengan kebutuhan manusia yang semakin pesat dan ingin yang praktis. Hal ini yang menyebabkan teknologi semakin beragam dan mudah untuk diaplikasikan.

Penggunaan Sistem Informasi Geografis (SIG) dan pengaplikasiannya dibantu melalui software ArcGIS sudah mulai berkembang terutama di Indonesia. SIG merupakan sistem informasi yang unik karena menggunakan data spasial, yang telah direferensikan sebagai input data serta informasi yang menghasilkan solusi untuk memecahkan masalah spasial yang mungkin tidak dapat diselesaikan dengan sistem informasi yang lain [3]. Dengan demikian, diharapkan keberadaan suatu sistem informasi yang efisien, lugas akan mampu mengelola data dengan struktur yang kompleks dan dengan jumlah yang besar ini dapat membantu dalam proses pengambilan keputusan yang tepat [1]. 
Pengelolan data informasi georeferensi atau pemetaan lokasi akan memudahkan penggunanya pada suatu area yang terhubung dengan database teknologi SIG [4]. Menariknya sebelum ini di Dusun belum pernah dibuatkan peta baik secara hard file ataupun soft file.

\section{METODE KEGIATAN}

Pengabdian ini dilakukan di Dusun Pokoh 1, Kecamatan Dlingo, Kabupaten Bantul pada tahun 2019. Dusun Pokoh 1 terdiri dari 4 rukun tangga (RT) dengan jumlah penduduknya sebanyak 127 KK (Kepala Keluarga).

Untuk memulai kegiatan ini langkah utama yang dilakukan oleh pengabdi adalah sosialisasi dan penjelasan kepada perangkat dukuh dan masyarakat mengenai peta ini mengingat belum ada peta kependudukan yang ada apalagi menggunakan teknologi seperti SIG.

Langkah kedua berupa pengimputan data sekunder berupa kartu keluarga yang terdapat di Kepala Dukuh menggunakan Microsoft excel. Data sekunder yang dimaksud adalah berupa data penting dimana untuk database pada sistem informasi desa yaitu berupa data kependudukan dan data pekerjaan kepala keluarga, usaha yang dijalankan, fasilitas umum seperti masjid, tempat wisata dll.

Langkah ketiga berupa survei lapangan dan penyesuaian / update data sekunder terhadap penduduk dengan cara datang langsung kerumah sekaligus pengambilan titik kordinat menggunakan GPS Garmin.

Sistem Informasi Geografis (SIG) merupakan sistem yang dirancang untuk bekerja dengan data yang tereferensi secara spasial atau koordinat-koordinat geografi
[5]. Saat ini teknologi SIG mengintegrasikan operasi pengolahan data berbasis database yang biasa digunakan seperti pengambilan visualisasi serta analisis geografis melalui gambar-gambar petanya [6]. Penggunaan Garmin Global Positioning Sistem (GPS) didasarkan pada konsep jangkauan dan trilaterasi dari sekelompok satelit, yang bertindak sebagai titik referensi yang tepat.[7]

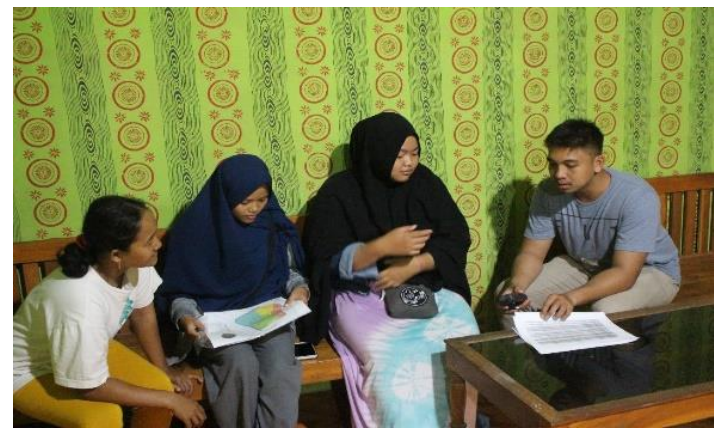

Gambar 1. Proses survei dan interview

Langkah ke empat merupakan tabulasi data, revisi dari hasil survei lapangan dan pengupdate-an data menggunakan Microsoft excel. Selanjutnya memulai penggambaran data menggunakan software ArcGIS. Setelah peta jadi akan di uji coba kesesuaian posisi dan koordinat agar tidak terjadi kesalahan yang jauh menyimpang dari posisi rumah mengingat di Dusun untuk jaringan GPS tidak terlalu baik sehingga menyebabkan pengambilan satu buah data koordinat pelaksana bisa menghabiskan waktu paling tidak setengah jam.

Langkah ke lima memberikan pelatihan kepada pemuda untuk penggunaan software, dan bagaimana memperbaharui data.

Langkah terakhir adalah sosialisasi kepada masyarakat dan pencetakan peta yang nantinya akan diserahkan kepada Kepala Dukuh. Serta mengaitkan tautan ke website Desa.

Adapun penjelasan dan langkahlangkah pembuatan database menggunakan software ArcGIS:

1. Pengolahan data dengan mendownload file peta RBI 


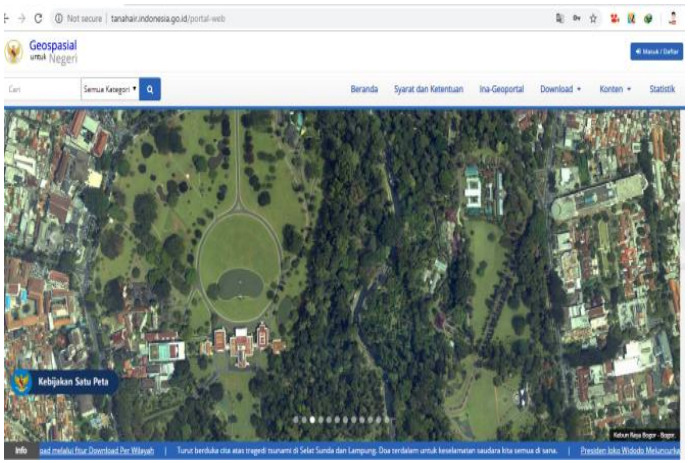

Gambar 2. Tampilan halaman web geospasial

2. Sesudah peta RBI di download, simpan dan extrackfile-nya dalam sebuah folder yang sudah ditentukan. Peta RBI menjadi peta dasar yang memberikan informasi secara khusus untuk wilayah darat. Peta Rupabumi Indonesia (RBI) saat ini adalah hal yang sangat dinantikan dan paling selalu digunakan oleh masyarakat sebagai pengguna Informasi Geospasial. Kualitas yang baik menjadi tuntutan utama dalam pembuatan peta RBI, termasuk peta RBI skala besar [8]

\begin{tabular}{|c|c|c|c|}
\hline m & 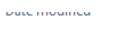 & יוני & vace \\
\hline [] JEMBATAN_PT_25K.sbn & 01/03/2018 12.16 & SBN File & $9 \mathrm{~KB}$ \\
\hline ] JEMBATAN_PT_25K.sbx & 01/03/2018 12.16 & SBX File & $1 \mathrm{~KB}$ \\
\hline D JEMBATAN_PT_25K & $01 / 03 / 201812.16$ & AutoCAD Shape S... & $37 \mathrm{~KB}$ \\
\hline JEMBATAN_PT_25K.shp & 01/03/2018 12.16 & XML Document & $10 \mathrm{~KB}$ \\
\hline JEMBATAN_PT_25K & $01 / 03 / 201812.16$ & AutoCAD Compil... & $7 \mathrm{~KB}$ \\
\hline 寻 KAB. BANTUL & 15/01/2019 14.16 & WinRAR ZIP archive & $10.396 \mathrm{~KB}$ \\
\hline KABELLISTRIK_LN_25K.cpg & $01 / 03 / 201812.16$ & CPG File & $1 \mathrm{~KB}$ \\
\hline KABELLLITRIK_LN_25K.dbf & $01 / 03 / 201812.16$ & DBF File & $2 \mathrm{~KB}$ \\
\hline KABELLISTRIK_LN_25K.prj & $01 / 03 / 201812.16$ & PRU File & $1 \mathrm{~KB}$ \\
\hline KABELLISTRIK_LN_25K.sbn & $01 / 03 / 201812.16$ & SBN File & $1 \mathrm{~KB}$ \\
\hline KABELLISTRIK_LN_25K.sbx & 01/03/2018 12.16 & SBX File & 1 KB \\
\hline KABELLISTRIK_LN_25K & 01/03/2018 12.16 & AutoCAD Shape S... & $2 \mathrm{~KB}$ \\
\hline I] KABELLISTRIK_LN_25K.shp & 01/03/2018 12.16 & XML Document & $8 \mathrm{~KB}$ \\
\hline KABELLISTRIK_LN_25K & $01 / 03 / 201812.16$ & AutoCAD Compil... & $1 \mathrm{~KB}$ \\
\hline KANTORPOS_PT_25K.cpg & 01/03/2018 12.16 & CPG File & $1 \mathrm{~KB}$ \\
\hline KANTORPOS_PT_25K.dbf & $01 / 03 / 201812.16$ & DBF File & $10 \mathrm{~KB}$ \\
\hline KANTORPOS_PT_25K.prj & $01 / 03 / 201812.16$ & PR File & $1 \mathrm{~KB}$ \\
\hline
\end{tabular}

Gambar 3. Mengekstrak file peta RBI

3. Buka ArcGIS dengan klik aplikasi pada ArcMap.

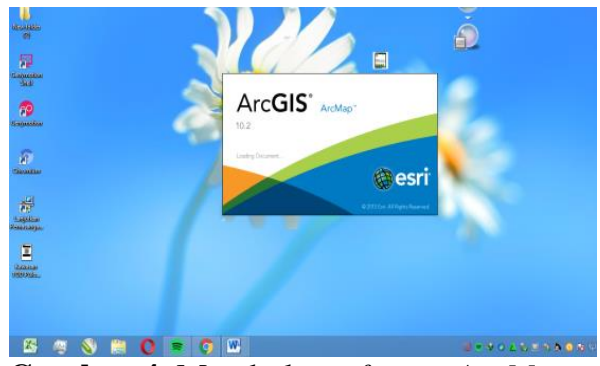

Gambar 4. Membuka software ArcMap
4. Membuat file baru dengan memilih New Document pada tampilan awal dan pilih Blank Map lalu klik $O K$.

Q. Untitle

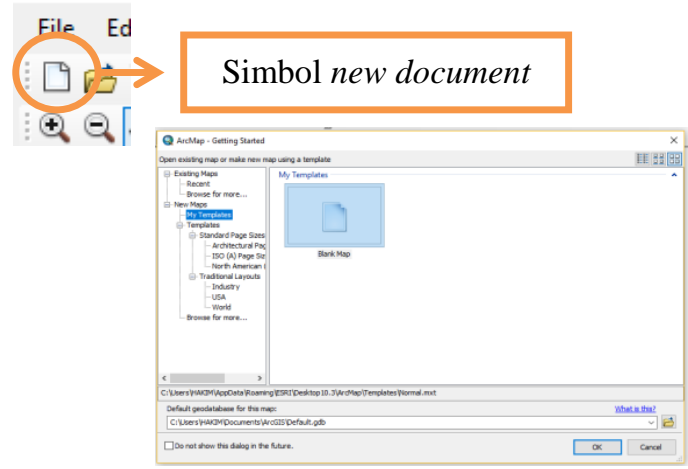

Gambar 5. Membuat dokumen baru pada ArcMap

5. Klik add data dan pilih file pada folder peta RBI yang sudah di extrack tadi, lalu klik add.

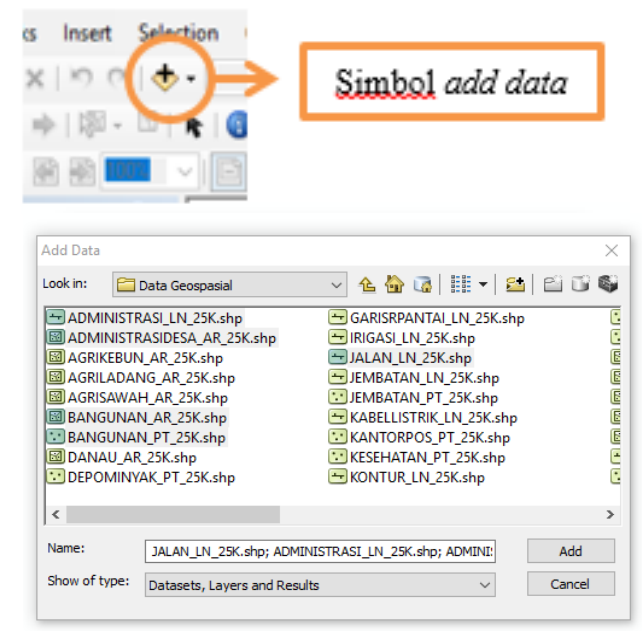

Gambar 6. Add data peta RBI

6. Peta akan muncul pada tampilan aplikasi ArcMap yang digunakan.

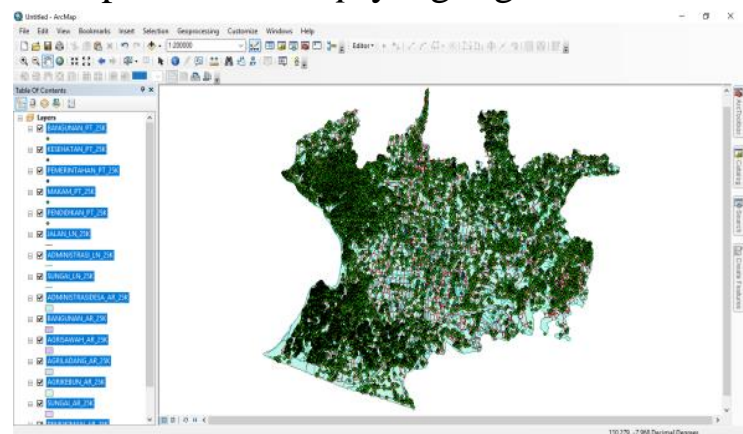

Gambar 7. Tampilan peta data RBI pada ArcMap 
7. Setelah selesai memasukkan peta RBI ke ArcMap, kemudian tentukan daerah Dusun Pokoh 1 dan ambil data yang ingin digunakan.

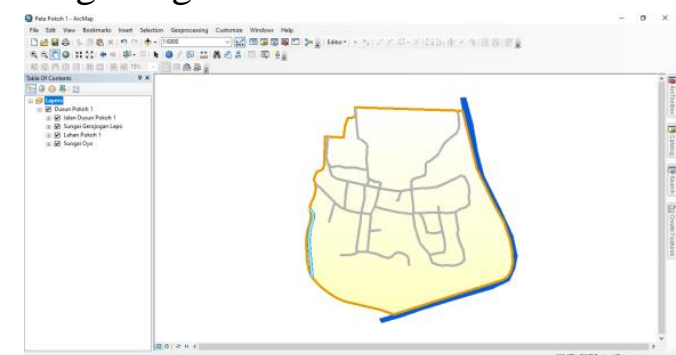

Gambar 8. Tampilan daerah Dusun Pokoh 1 pada ArcMap

8. Kemudian masukan koordinat yang di ambil pada Dusun Pokoh 1 dan disimpan dalam microsoft excel dengan format file excel 97-2003 Workbook. Koordinat bujur-lintang maupun UTM (Universal Transverse Mercator) yang diinput pada software ini merupakan hasil identifikasi menggunakan alat GPS sehingga dapat diketahui ketepatannya secara visualisasi spasial. Sistem ini didesain untuk memberikan posisi dan kecepatan tiga dimensi serta informasi mengenai waktu secara berkelanjutan di seluruh dunia tanpa tergantung waktu dan cuaca kepada banyak orang secara simultan.

9. Kemudian, input data yang sudah disimpan dengan cara pilih Add Data dan klik Add XY Data. Hal ini dilakukan pada setiap langkah awal input data berupa koordinat yang sebelumnya sudah disiapkan dalam format excel.

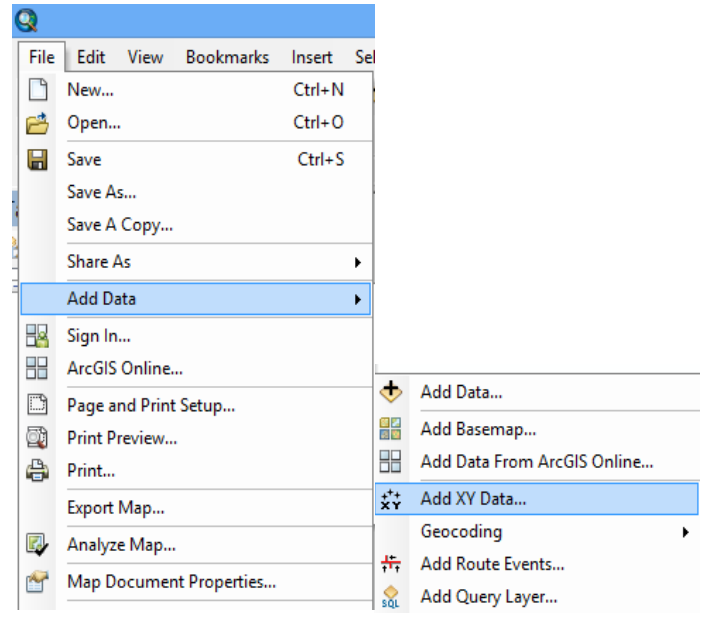

Gambar 9. Membuka menu add data

10. Pada kotak dialog Add XY Data, masukan data Excel yang disimpan tadi. Pada menu edit pilih WGS_1984_UTM_Zona_49S karena daerah lokasi Dusun Pokoh 1 berada pada lokasi tersebut kemudian klik OK

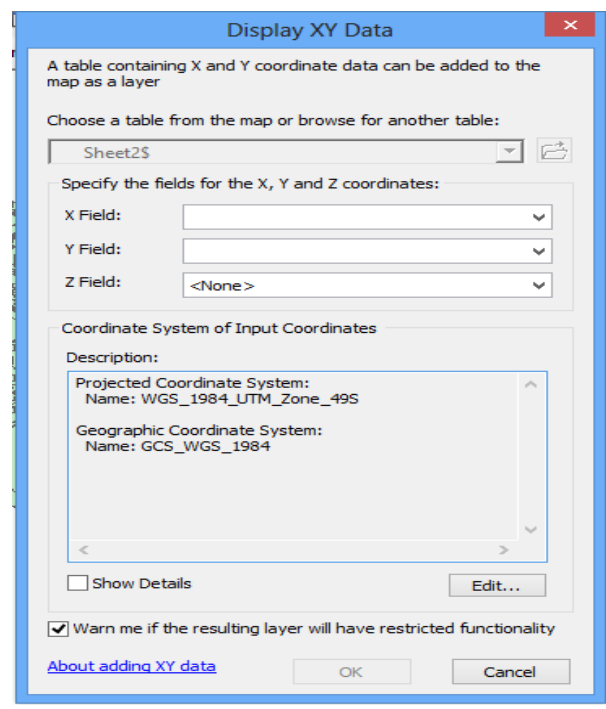

Gambar 10. Memasukkan data koordinat

11. Setelah data koordinat sudah diinput lalu ubah data tersebut yang berformat excel menjadi shapefile, dengan cara klik kanan pada data tersebut kemudian klik Data lalu pilih Export Data. 


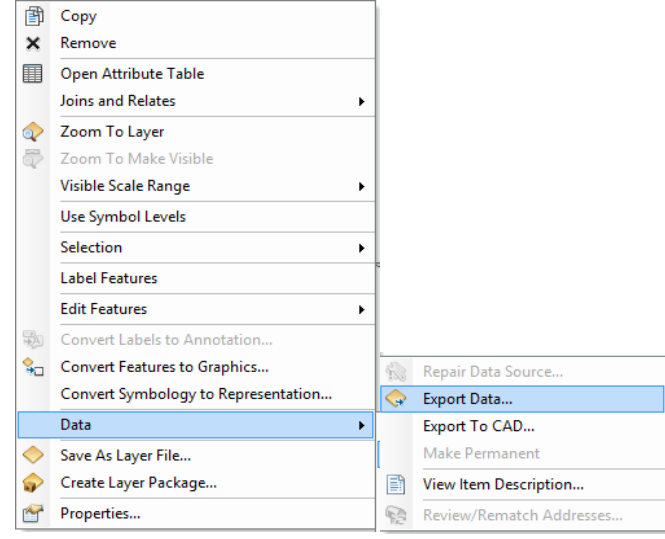

Gambar 10. Tampilan menu data

12. Kemudian akan terbuka kotak dialog Export Data pada bagian Output Feature Class pilih folder yang akan digunakan untuk menyimpan data tersebut lalu klik OK.

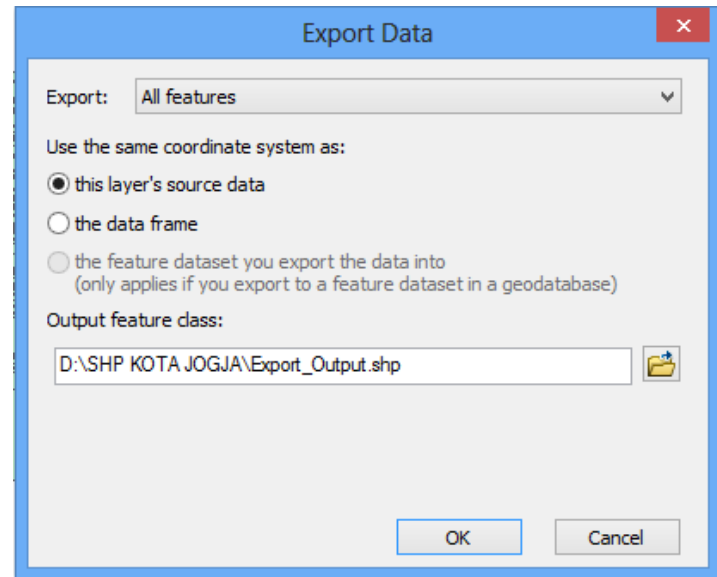

Gambar 11. Tampilan jendela export data

13. Setelah semua data sudah di input ke dalam ArcMap ubah tampilan data tersebut dan masukan skala, legenda dan notasi lain yang diinginkan. Penetapan atribut peta tersebut disesuaikan dengan keinginan pengguna berdasarkan kebutuhan informasi mana yang akan disampaikan. Namun pada umumnya, skala dan legenda merupakan input utama yang harus ada pada peta.

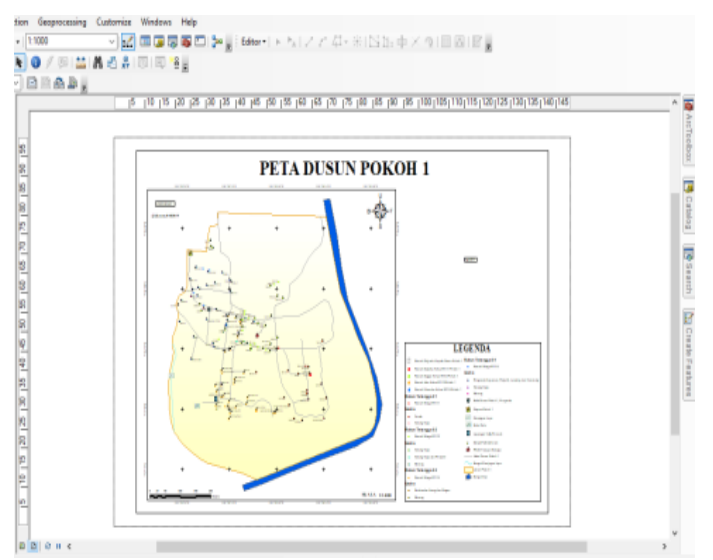

Gambar 12. peta Dusun Pokoh 1 setelah data di input dan diberi notasi

Setelah pemetaan pada software ArcGIS desktop selesai maka selanjutnya masuk ketahap pembuatan peta yang dapat dilihat secara online oleh seluruh warga sekalipun mereka tidak mempunyai software ArcGIS.

14. Langkah pertama adalah create acount, kemudian masukkan username dan password, kemudian masuk ke akun.

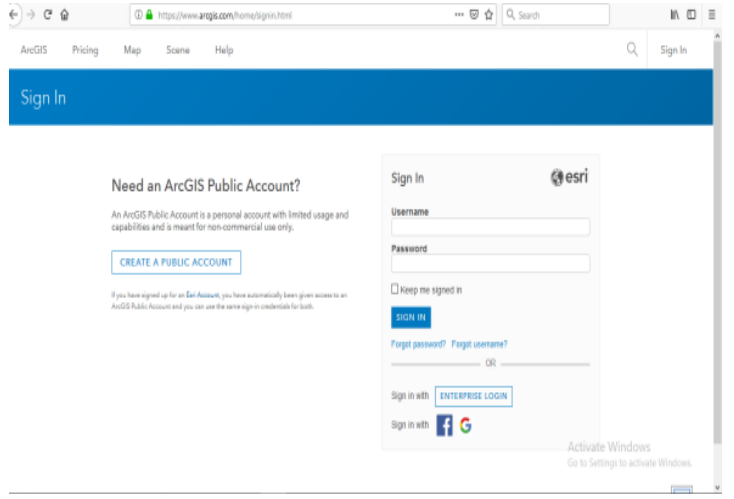

Gambar 13. Tampilan untuk memasukkan username dan password

15. Setelah akun ArcGIS online sudah terbuka, berikutnya adalah memasukkan file shp yang akan digunakan untuk membuat base map. Caranya klik add item kemudian pilih file yaitu shp dari file ArcGIS yang telah dibuat sebelumnya. 


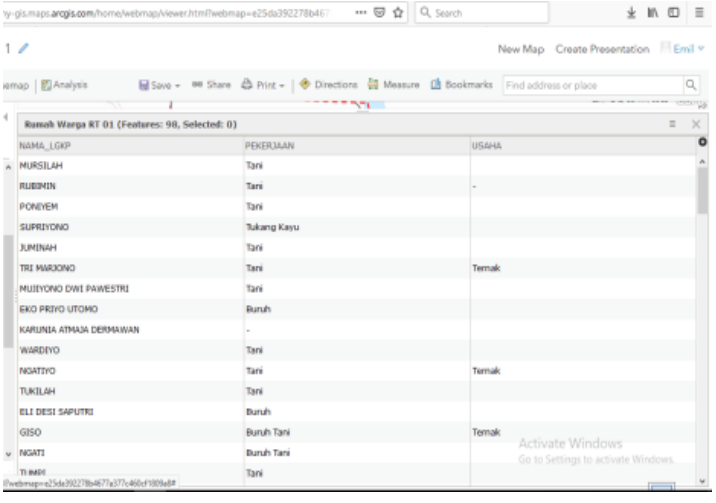

Gambar 14. Tampilan untuk file shp dari file ArcGIS yang telah dibuat sebelumnya.

16. Setelah file terunggah kemudian file shp masih perlu untuk diatur secara letak nya. Hal ini agar pengguna lebih mudah dalam pembacaan data shp yang dibuat dalam ArcGIS online karena pada akhirnya banyak pengguna yang akan mengakses base map tersebut. Sehingga, dalam pengaksesan datanya dapat diminimalisir kekeliruannya khususnya dalam peng-update-an data peta

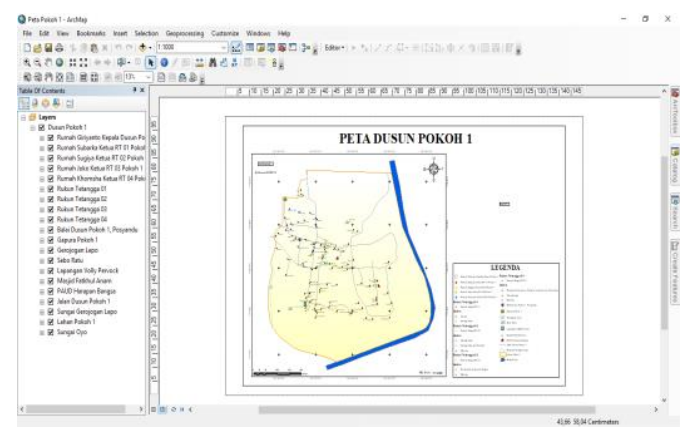

Gambar 15. Tampilan peta

17. Setelah semuanya sesuai, kemudian save web. Lalu akan keluar link untuk dibagikan dan siapa saja dapat melihat peta tersebut.

Adapun link yang dihasilkan dari kegiatan ini terdiri dari data kependudukan yang hanya bisa di pegang oleh Kepala Dukuh dan satu buah link yang boleh diakses oleh siapa saja: https://arcg.is/19uqWn.

\section{KARYA UTAMA}

Peta sebagai model bagian dari permukaan bumi yang menunjukkan bagaimana bentuk, dan posisi berbagai negara, fitur alam seperti sungai dan pegunungan, dan fitur buatan seperti jalan dan bangunan. Sebuah peta juga dapat memberi kita jenis informasi tertentu tentang suatu wilayah tertentu di permukaan bumi [9]. Secara umum, sistem GIS telah dipuji memungkinkan input, penyimpanan, dan manipulasi geospasial yang cepat dalam hal informasi informasi. Banyak lembaga dan perusahaan telah melakukan investasi yang signifikan dalam teknologi sistem informasi geografis (GIS) [10].

Peta digital berbasiskan ArcGIS yang dihasilkan ini masih bersifat online sehingga untuk membukanya kita memerlukan jaringan internet, namun untuk isian bisa disesuaikan dan diinput sesuai dengan kebutuhan pengguna. Teknologi yang digunakan untuk membuat peta ini memaksa masyarakat dusun dan sekitarnya untuk lebih melek terhadap teknologi, agar perangkat kecil seperti dusun tidak tertinggal oleh perkembangan.

Sebanyak $170 \mathrm{KK}$ yang tersebar di Dusun Pokoh 1 namun tidak berarti sebanyak itu pula notasi rumah yang ditampilkan di peta digital di atas. Hal tersebut dikarenakan terdapat beberapa kepala keluarga yang berdiam disatu rumah yang sama. Rumah dan tempat ibadah diberikan notasi yang berbeda. Hal ini dilakukan supaya bisa membedakan dan mempermudah akses menuju ke fasilitas umum seperti masjid, balai desa, air terjun (grojogan) Lepo, sekolah dan sungai, bahkan lapangan olahraga. 


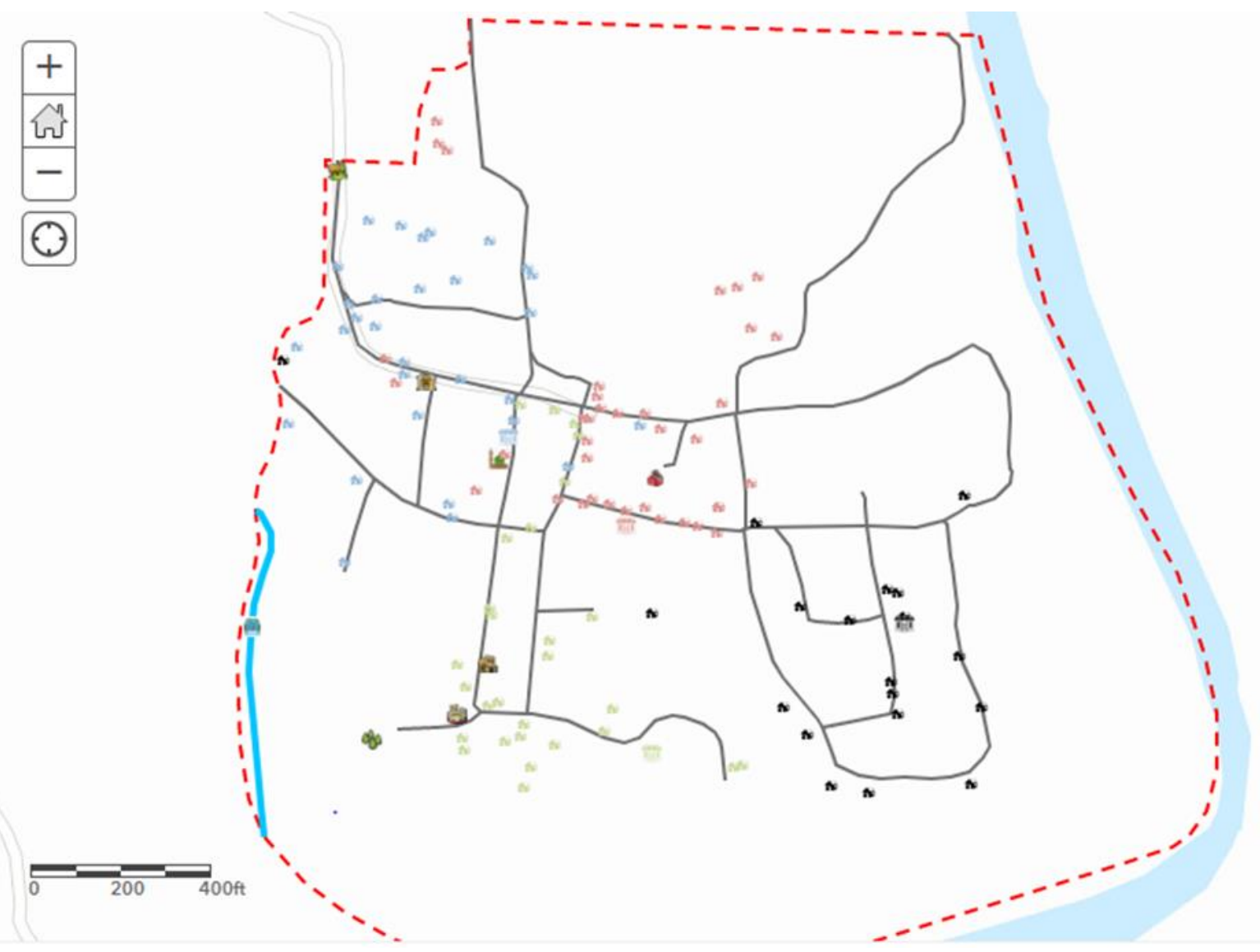

Gambar 16. Peta Digital Dusun Pokoh 1

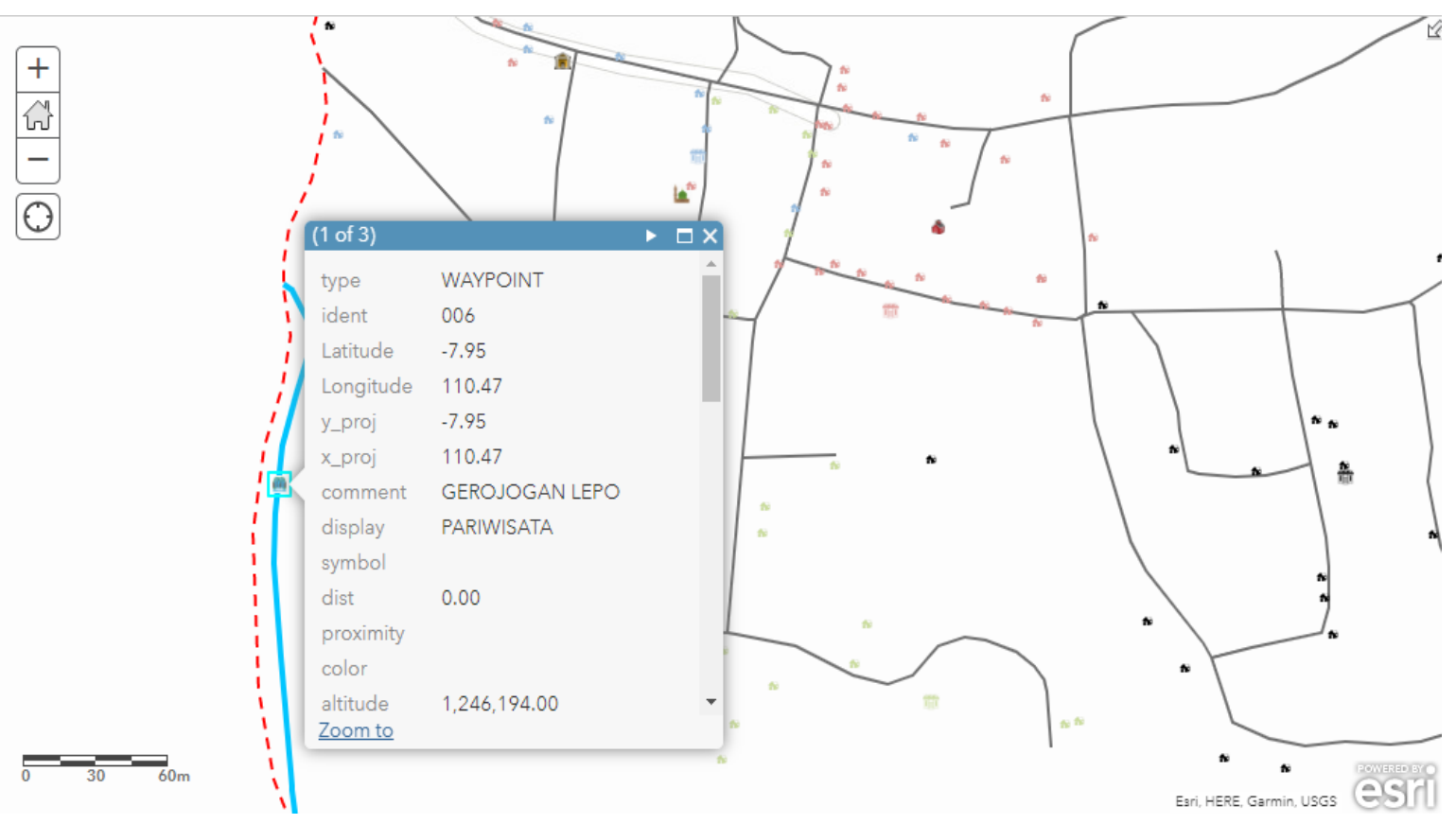

Gambar 17. Data visual jika salah satu notasi diklik 
Dari Gambar 16 dan 17 di atas adalah salah salah satu bukti penggunaan system informasi kependudukan dan wisata yang sangat mudah yang bisa dihasilkan oleh bantuan teknologi SIG. Dengan klik notasi ataupun nomer rumah atau fasilitas lainnya maka data dan informasi yang ada di lokasi tersebut akan muncul dan bisa diketahui.

Akurasi yang dihasilkan oleh GPS Garmin lebih baik jika menggunakan handphone. Pada pengambilan data ini bisa diambil kesimpulan bahwa terjadi kurang lebih 5\% eror yakni koordinat rumah bergeser tiga hingga lima meter, namun masih masuk dalam Kawasan/halaman rumah warga, hal ini di sebabkan oleh sulitnya jaringan telekomunikasi yang berdampak kepada GPS Garmin.

Dari Peta digital di atas juga terlihat jelas bahwa jaringan jalan di Dukuh tergambar dengan sangat baik. Hal ini akan sangat mendukung aksesibilitas bagi siapa saja yang keluar masuk dikawasan tersebut.

Aksesibilitas adalah hal vital yang harus dimiliki sebagai prasarana pendukung utama dalam perkembangan suatu wilayah, terlebih lagi jika suatu wilayah tersebut akan dikembangkan menjadi suaru daerah pariwisata yang unggul.

Dengan link atau tautan yang diberikan atau sesiapa yang mendapatkan link peta ini, maka mereka akan dapat dengan mudah mengakses lingkungan di Dusun, dan bagi Kepala Dukuh mendapatkan informasi yang lebih lengkap terkait penduduknya sesuai dengan input data yang ada di Kartu Keluarga (link khusus Kepala Dukuh) karena data bersifat rahasia dan tidak boleh dibagikan tanpa kebenaran.

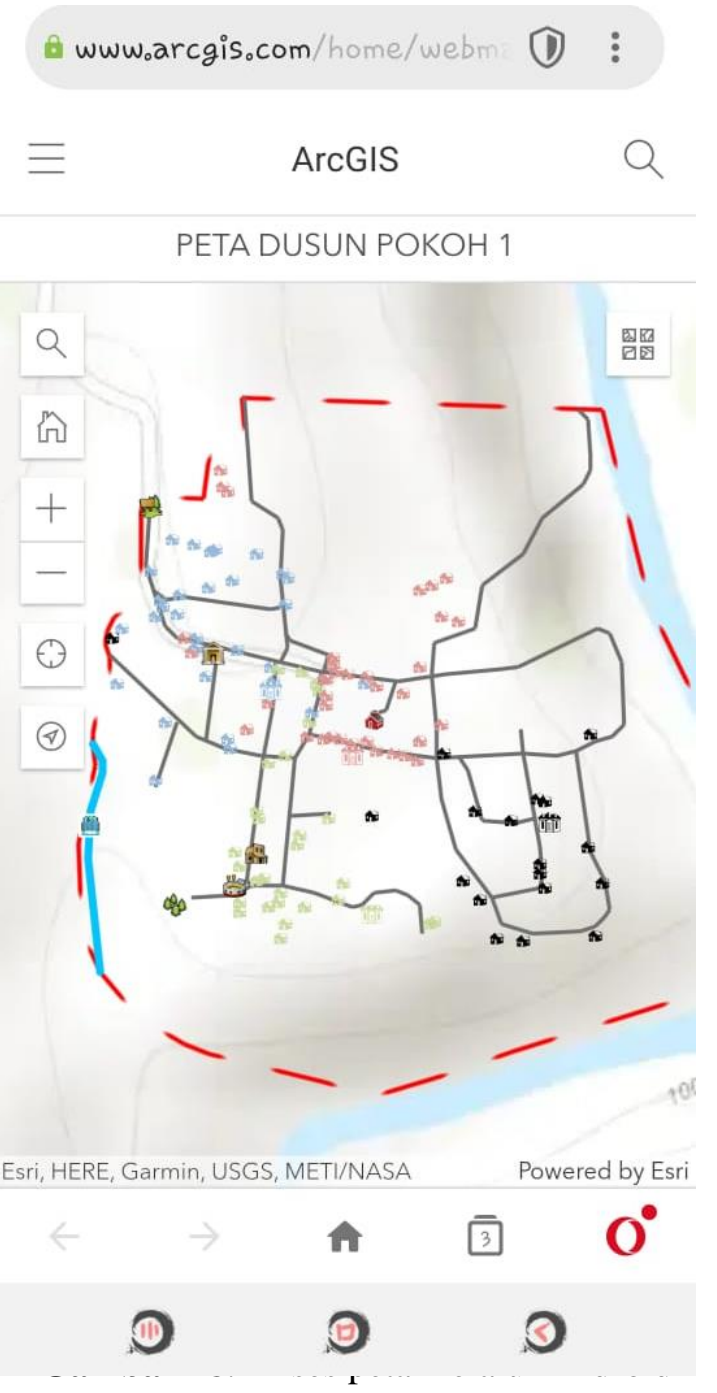

\section{ULASAN KARYA}

Peta dalam bentuk database ini sangat membantu dalam mengefisienkan kerja agar dapat cepat dalam mengakses data dan membuat tabulasi data kependudukan dusun. Dalam hal ini perangkat Dusun dan warga sangat terbantu untuk keefisienan waktu mereka. Jika sebelumnya mereka harus mengakses database melalui kantor kelurahan atau kantor kecamatan, maka sekarang akan lebih efisien dengan hanya mengakses link yang telah ditautkan dengan database online. 
Kelemahan karya ini adalah dalam penggambaran belum terlihat deliniasi antar RT di dukuh hal ini disebabkan pada saat pengambilan batas yang ditunjukkan perangkat Dusun dan masyarakat masih banyak pohonan yang rindang sehingga tidak bisa mengakses GPS Garmin dengan maksimal sehingga pelaksanaan memutuskan untuk tidak memberikan deliniasi.

Bagi pengguna yang melek teknologi tidak akan kesulitan dalam mengakses database tersebut, namun bagi masyarakat awam perlu mempelajarinya terlebih dahulu dari pada mengakses data berbasis offline seperti peta hardfile atau data yang diperoleh dari kantor kelurahan atau kantor kecamatan.

Untuk selanjutnya peta ini bisa dikembangkan kembali menggunakan aplikasi CarryMap yang lebih baik tampilannya. CarryMap merupakan sebuah aplikasi open-source yang digunakan untuk mendesain dan menampilkan peta sederhana hingga kompleks yang portabel sehingga mudah digunakan oleh orang awam [11] dan pengguhnaannya bersifat offline.

Pemuda yang sudah mengikuti program pelatihan yang sebelumnya diberikan sudah mampu untuk mengoprasikan dan mengolah administrasi data-data kependudukan yang tersaji dalam sistem ArcGIS yang telah dikembangkan dalam sistem online dan disajikan dalam bentuk peta, sehingga untuk selanjutnya masyarakat yang sudah dibekali ilmu pengoprasian data administrasi dapat untuk mengupdate secara berkala.

\section{DAMPAK DAN MANFAAT KEGIATAN}

Dampak dari kegiatan ini adalah bahwa database yang dihasilkan bersifat online, sehingga sangat membutuhkan koneksi internet. Teknologi ini menampilkan peta beserta dengan informasi yang ada secara baik dan interaktif. Sistem informasi geografis yang dirancang digunakan dalam pengolahan data lokasi Dukuh di bawah naungan Desa Dlingo Bantul dan dalam mengoperasikan sistem ini pengguna harus mengikuti ketentuan yang ada.

Banyak pengembangan Desa untuk memberikan bantuan baik dalam bentuk CSR ataupun bantuan pemerintah. Dengan aplikasi peta ini maka perangkat Desa bahkan Dukuh akan lebih mudah memberikan informasi dengan cepat dan akurat tanpa harus membuka tumpukan kertas yang bisa rusak dan usang dimakan waktu. Selain itu, untuk dapat mengakses ArcGIS online tidak membutuhkan akun baru bagi pengguna yang ingin mengakses karena sudah disetting sedemikian rupa sehingga bisa diakses dimana saja sepanjang jaringan internet bisa diakses.

Namun, dari dampak tersebut terdapat manfaat yang akan dirasakan oleh masyarakat bahwa dalam pencarian data yang bersifat dinamis tersebut dapat diupdate dengan mudah, sehingga, diharapkan informasi yang tersaji dalam web Desa lebih up to date dengan kondisi eksisting. Link/tautan telah diberikan kepada perangkat desa, sehingga apabila sudah tartempel pada website Dusun maka siapa saja akan bisa mengakses Dusun dengan mudah, apalagi dalam proses pencarian tempat wisata yang ada. 


\section{KESIMPULAN}

Teknologi menggunakan ArcGIS telah banyak membantu pengguna dalam pembuatan peta digital. Masyarakat dipermudah dalam mengakses, melihat, pengumpulan data kependudukan, sesuai dengan input yang diberikan pada ArcGIS. Masyarakat yang memiliki link/tautan dapat mengetahui secara rinci letak rumah warga besertakan data-data kependudukannya yang telah tersedia dalam bentuk online dan dalam bentuk peta. Selain itu masyarakat mendapat soft skill tentang pembuatan dan pengupdatean software ArcGIS.

\section{PENGHARGAAN}

Ucapan terimakasih yang sebesarbesarnya diberikan kepada Universitas Muhammadiyah Yogyakarta yang telah mendanai kegiatan ini sehingga kegiatan ini dapat terlaksana tanpa ada kendala yang berarti. Dan kepada pihak mitra semoga apa yang telah diterapkan bisa berguna dan menjadikan desa lebih maju dan tanggap terhadap teknologi dan informasi.

\section{DAFTAR PUSTAKA}

[1] E. Harseno and V. I. R. Tampubolon, "Aplikasi Sistem Informasi Geografis Dalam Pemetaan Batas Administrasi, Tanah, Geologi, Penggunaan Lahan, Lereng Daerah Istimewa Yogyakarta Dan Daerah Aliran Sungai Di Jawa Tengah Menggunakan Software Arcview Gis," Maj. Ilm. Ukrim, Vol. 1/Th Xii/2007, Pp. 63-80.

[2] J. Karman and E. Crisdiyanti, "Geographical Information System Mapping Based on Android at Equal Senior High School In Lubuklinggau,"
IJISTECH Int. J. Inf. Syst. Technol., vol. 3, no. 1, p. 49, Nov. 2019.

[3] Irwansyah E (2013) Sistem informasi geografis: prinsip dasar dan pengembangan aplikasi. DigiBook Yogyakarta,

[4] H. Bahtiar and L. Kerta Wijaya, "Mobile Based Geographic Information System for mapping and data collection Towards 4.0 Industry," J. Phys. Conf. Ser., vol. 1539, p. 012012, May 2020.

[5] W. N. Rohim, M. Awaluddin, and A. Suprayogi, "Jurnal Geodesi Undip," p. 14, 2015.

[6] I. K. A. Ady Aryanto and N. M. I. Marini Mandenni, "Sistem Informasi Geografis Letak Puskesmas di Wilayah Kabupaten Tabanan Berbasis Web," JTIM J. Teknol. Inf. Dan Multimed., vol. 1, no. 4, pp. 294-301, Feb. 2020.

[7] M. E. Ali, "Global Positioning System (GPS): Definition, Principles, Errors, Applications \& DGPS," no. April 2020, p. 20.

[8] Danang Budi Susetyo, Fahrul Hidayat, Tia Rizka N.R, Nadya Oktaviani, and Maslahatun Nashiha, "Analisis Kedetailan Peta Rupabumi Indonesia Multi-Skala," Semin. Nas. Geomatika, vol. 2, p. 551, Feb. 2018.

[9] I. S. Kolawole, T. A. Alaga, S. A. Ogunyemi, O. S. Popoola, and M. O. Oloko-Oba, "Street Mapping of Ife Metropolis, Osun State, Nigeria," J. Geogr. Inf. Syst., vol. 08, no. 03, pp. $387-$ 395, 2016.

[10] F. L. Ogden, J. Garbrecht, P. A. DeBarry, and L. E. Johnson, "GIS and Distributed Watershed Models. II: Modules, Interfaces, and Models," J. Hydrol. Eng., vol. 6, no. 6, pp. 515-523, Dec. 2001.

[11] W. Justian and M. Taufik, "Potency Analysis of the Batik MSMES Industrial in Surabaya Using Geographic Information System," IPTEK J. Proc. Ser., vol. 0, no. 2, p. 6, Jun. 2019. 
